\title{
Affirmative Action and Substantive Equality in the Academia: Female Students' Perspective the Case of Raya University
}

\author{
Teklu G/medhin \\ College of Social Science and Humanities, Raya University, Po Box 92, Tigrai, Ethiopia \\ Mulu Bzayene \\ College of Social Science and Humanities, Raya University, Po Box 92, Tigrai, Ethiopia
}

\begin{abstract}
The study was conducted in Raya University, Ethiopia with a prime objective to assess and analyze the role of affirmative action program in improving female students' academic achievement. Both quantitative and qualitative research approaches were employed in this study. Besides primary and secondary data sources were utilized. Proportional stratified sampling method was employed to determine sample size. Thus, 120 female students were participated in the study as primary data source from which the required data was generated. Besides 10 female instructors was included using purposive sampling method to validate and cross check the idea of female students. Multiple data collection instruments were utilized in the data collection process which includes questionnaire, interview and document analysis. The finding revealed tutorial class, material support and department placement are implemented to enhance female students' academic achievement. Even though female students have positive perception towards the program they claimed that the program is not well organized and ineffective in its implementation. Thus, substantive equality is not assured in the academia between male and female students. This is in line with the document analysis result in which female students disproportionately scores lower academic result than their male counterparts. Economic problem, cultural barrier and lack of self-confidence of females are the most contributory factors for their failure. In view of these the researchers recommends capacity building schemes such as financial support, counseling service, tutorial class and awareness creation activities to be given due attention by concerned stakeholders for female students to minimize their challenges and enhance the effectiveness of affirmative action programs in higher education institutions.
\end{abstract}

Keywords: Academia, Affirmative action, Female students, Substantive equality

DOI: $10.7176 / \mathrm{JEP} / 10-16-09$

Publication date:June $30^{\text {th }} 2019$

\section{Introduction}

It is fact that women comprise half of the world population (Yasin, 2013). Even though, women have no access to education; training, employment and political participation reinforced by stereotypical attitudes (Yasin, 2013). Specifically, Melese \& Fenta (2009) show that socio-economic and cultural factors inhibit girls' access to education in the primary and secondary levels effectively and cut off their access to tertiary education. In Ethiopia, from among 950 students joined to Addis Ababa University, 39 of them were female students in 1962 and there were 15 female graduates from 246 students in 1982 (Semela, 2007).

To address these challenges, the current government of Ethiopia has taken policy and strategy measures. Article 35 (8) of the FDRE constitution is among the measures that states women have the right to equality in employment, promotion, payment and the transfer of pension entitlement. The Ethiopian Education and Training Policy (1994) also promote an education system in a way to address the cultural and traditional problems in order to benefit females in education. Despite of these efforts, female students are not still competent both in quality and quantity as per to the required standard. Because of this, the government has adopted affirmative action program to support and encourage female students especially those who join to preparatory school, TVET colleges, teacher training colleges and universities. So, what are the challenges that face by female students to come up with the necessary knowledge and skill and compete with their male partners confidentially was the concern of the study.

Recently, Ethiopian government adopts affirmative action programs to minimize the gender gap and ensure equal opportunity in all rounded aspects of men's and women's life particularly in education and the number of female students in higher education institutions increases accordingly. Joining to higher education institutions, however, is not an end by itself. This is because it may help students to get a foot in the door, but they have to walk through the door by themselves (Rowland, 1997). Hence, as far as the researchers' knowledge is concerned, female students' level of vulnerability to gender inequality is still persistent in Ethiopia. Therefore, this study aimed to investigate the effectiveness of affirmative action to improve female students' academic achievement. The study mainly concerns to assess the effect of affirmative action on female student's academic performance and promoting substantive equality by revealing the experience of Raya University. Take in to 
consideration this general objective; the following specific objectives were addressed by the study.

* Assess the implementation of affirmative action program;

* Investigate female students' awareness on the significance of affirmative action;

* Assess the role of affirmative action on female students' academic achievement;

\section{Research Methodology}

To conduct this study cross sectional descriptive survey design was employed. In terms of research approach, mixed approach (both quantitative and qualitative methods) was utilized. Regarding sampling technique proportional stratified sampling method was employed to ensure representativeness and reliability. Respondents were categorized into five strata based on their college. This method is preferable to have better exposure about the implementation of post-admission affirmative action program in the University. Finally using simple random sampling technique 120 respondents were participated in the study. Besides, purposive sampling was employed to select samples from female instructors. Hence, ten female instructors were selected based on their work experience and position they have in the University.

To collect the necessary data for this study, multiple data collection instruments were used because no single method can guarantee 100 percent accurate data. For the purpose of this study questionnaire, interview and document analysis were employed. Interview was employed to investigate more information about female students' academic achievement with open-ended items from female instructors and gender officer. Furthermore, document analysis was utilized to reveal the academic achievement of participants. Besides, descriptive statistics and qualitative analysis (narration of ideas, attitudes and perceptions) were employed in the study as data analysis techniques. Hence, descriptive statistics, such as minimum, maximum, frequency, percentages and mean was used. Besides, qualitative analysis (narration) was employed to diagnose perception and attitude of female instructors about their response from the interview checklist. During data analysis process SPSS version 20.0 was used as data analysis tool.

\section{Result and Discussion}

\section{Demographic characteristics of participants}

This section discusses demographic characteristics of female students. Issues addressed in this section include age and marital status of respondents. As indicated in table 1, in terms of age of participants the finding revealed that the minimum and maximum value was 18 and 23 respectively while 19.68 is the mean. This indicates that most of the students are based on training and education policy age level of the country. Regarding the marital status of participants $96.7 \%$ of the participants were unmarried. This indicated that education contributes to minimize early marriage of females.

\section{Affirmative action supportive programs in higher education}

In higher education institutions, there are different programs that designed to support female students to improve their academic performance. Of these programs affirmative action/positive discrimination is one among others. The purpose of the researchers was to assess what types of supportive programs are applied in the university. The following table illustrates about this issue.

Table 1: Supportive program/s implemented to assist female students

\begin{tabular}{|l|c|c|}
\hline \multicolumn{1}{|c|}{ Supportive program/s } & Frequency & Percent \\
\hline Tutorial class & $\mathbf{5 8}$ & $\mathbf{4 8 . 3}$ \\
\hline Material support & 14 & 11.7 \\
\hline Department placement & 13 & $\mathbf{1 0 . 8}$ \\
\hline All & 11 & $\mathbf{9 . 2}$ \\
\hline No support & $\mathbf{2 4}$ & $\mathbf{2 0 . 0}$ \\
\hline Total & $\mathbf{1 2 0}$ & $\mathbf{1 0 0 . 0}$ \\
\hline
\end{tabular}

As indicated in table 1, majority of the participants (48.3\%) said that tutorial class is the common program provided for female students as a supportive program. In addition there were participants who confirmed that female students got material support, department placement priority and they have an opportunity to get all (tutorial, material support and department placement priority) as alternative supportive programs which are composed of $11.7 \%, 10.8 \%$ and $9.2 \%$ respectively. Out of the total participants, $(24$ or $20 \%$ ) of them revealed that there were not support programs that designed to assist female students' academic achievement. This shows that significant number of participants were less aware and not informed about the special programs they have in higher education institutions (both admission and post-admission programs) which designed to improve their academic achievement and increase highest ratio of graduating rate.

In terms of their participation in the program/s delivered by the university, majority of them $(50.8 \%)$ claimed that they were not beneficiaries. The main reason behind is there was no support that delivered for female students in the university. While $49.2 \%$ of the total participants confirmed that they participate in different affirmative action programs (table 2 below). So that participants were not well informed regarding the 
supportive programs that delivered for them at university level like the priority in department placement and tutorial class.

Table 2: Are you a beneficiary of the affirmative action program given in the University?

\begin{tabular}{|l|l|l|}
\hline Level of participation in the program & Frequency & Percent \\
\hline No & 61 & $\mathbf{5 0 . 8}$ \\
\hline Yes & 59 & 49.2 \\
\hline Total & 120 & 100.0 \\
\hline
\end{tabular}

According to table 3 (below), about $38(64.4 \%)$ of the respondents stated that they participated in tutorial classes, $15(25.4 \%)$ reported that they used affirmative action program in department selection and $6(10.2 \%)$ participants claimed as they got material support.

Table 3: If you are benefiting, in which program do you participate?

\begin{tabular}{|l|c|c|}
\hline Benefiting program & Frequency & Percent \\
\hline Tutorial class & 38 & 64.4 \\
\hline Material support & 6 & 10.2 \\
\hline Department placement & 15 & 25.4 \\
\hline Total & 59 & 100.0 \\
\hline
\end{tabular}

Awareness of female students about affirmative action programs

To assess the awareness of participants concerning supportive programs the researchers tries to investigate their perception with five point Lickret Scale item and the finding is illustrated in the following table.

Table 4: Perception of participants towards affirmative action program/s?

\begin{tabular}{|l|c|c|}
\hline Perception of participants & Frequency & Percent \\
\hline Very good & 43 & 35.8 \\
\hline Good & 19 & 15.8 \\
\hline Medium & 22 & 18.3 \\
\hline Low & 15 & 12.5 \\
\hline Very low & 21 & 17.5 \\
\hline Total & 120 & 100.0 \\
\hline
\end{tabular}

As shown in table $4,35.8 \%$ of the participants have very good attitude about the significance of affirmative action program in females' socio-economic life. Out of the total participants $18.3 \%$ and $15.8 \%$ confirmed their medium and good perception consecutively. To the contrary, $17.5 \%$ and $12.5 \%$ of the total participants in the study claimed that they have very low and low perception about affirmative action programs in higher education institutions. Thus, significant numbers of female students were not cognizant of the role of affirmative action programs play in their academic achievement which needs attention so as to improve such kind of attitude. This is because when they have negative attitude towards the role of affirmative action they cannot be beneficiaries of the program which is designed to support them.

Their perception has also an impact on their level of participation. When we see female students' effective participation in different affirmative action programs in higher education institutions, $47.5 \%$ of the total participants reported that they were not participating effectively. This may affect the intended goal of the program in terms of achieving better academic performance among female students and increase their level of graduating rate. The following table shows the most important challenges that affect their active and effective participation.

Table 5: Challenges that hinder their effective participation

\begin{tabular}{|l|c|c|}
\hline Challenges & Frequency & Percent \\
\hline Shortage of time & 16 & 28.1 \\
\hline Ineffectiveness & 9 & 15.8 \\
\hline Low perception & 8 & 14.0 \\
\hline No support & 24 & 42.1 \\
\hline Total & 57 & 100.0 \\
\hline
\end{tabular}

As it is indicated in the above table, $42.1 \%$ of the total participants claimed that there was no support that delivered for female students. While $28.1 \%$ reported as they face shortage of time which hinders their participation in the program. In addition, participants have shown the ineffectiveness of the program and their low perception towards affirmative action affects their active participation. In this regard there are divergent issues that challenge female students in higher education institutions.

Regarding female students' commitment to attend tutorial class majority of the participants $(63.3 \%)$ confirmed that they are very committed while $26.7 \%$ of them also agree their commitment (table 6 below). From this one can insist that female students have high commitment to improve their academic performance by participating in tutorial classes and other supportive programs. 
Table 6: Commitment of female students to attend tutorial class

\begin{tabular}{|l|c|c|}
\hline Commitment to attend tutorial class & Frequency & Percent \\
\hline Very committed & 76 & 63.3 \\
\hline Committed & 32 & 26.7 \\
\hline Weak & 8 & 6.7 \\
\hline Very weak & 4 & 3.3 \\
\hline Total & 120 & 100.0 \\
\hline
\end{tabular}

Concerning organization of affirmative action programs delivered in the university more than half $(57.5 \%)$ of the participants confirmed that it is less organized while $35.8 \%$ reported as medium (figure 1 below). This indicates that the program needs to be more organized and enhance its effectiveness. All stakeholders should take the leading position to make the program as their regular and continuous task so as to achieve the intended goal.

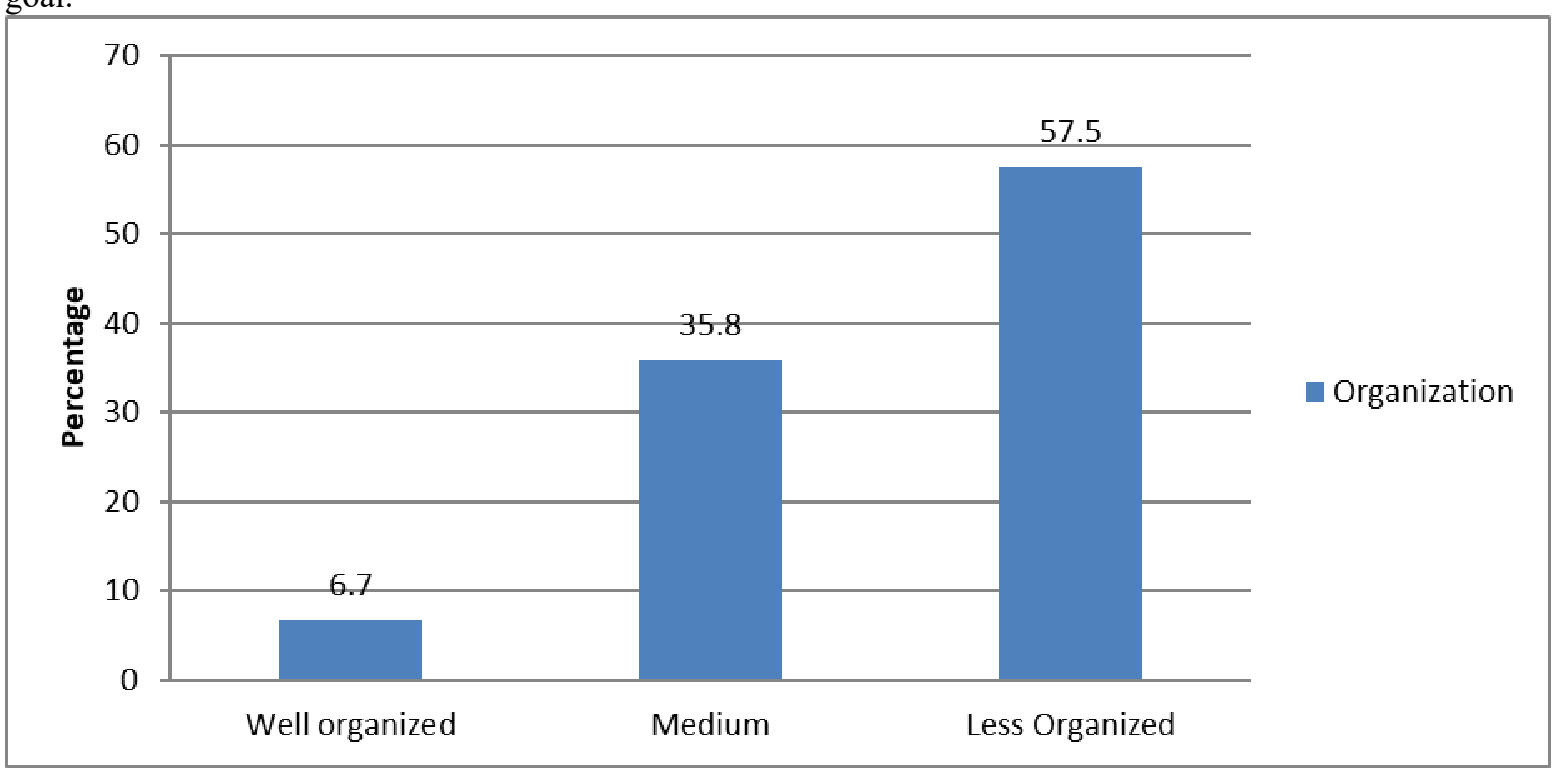

Figure 1: Organization of affirmative action program

The Effect of Affirmative Action on Female Students Academic Achievement

When we see the effectiveness of the program that designed to enhance female students' academic achievement, majority of the participants $43.3 \%$ reported that the program is ineffective while $40 \%$ of them stated as medium. In this case, even though the program is designed at national level and legal but there are weaknesses in terms of its implementation which enables to register the required level on the side of female students in higher education institutions.

As to figure 2 below, majority of the participants in the study (53.3\%) reported that there is no change that registered on the side of female students' academic achievement. On the other hand 25.8\% participants confirmed that the program helps to enhance the participation of female students in the teaching and learning process which considered as an important improvement. Out of the total participants in the study $14.2 \%$ and $6.7 \%$ reported as it enables to improve female students' self-confidence and their academic status. 


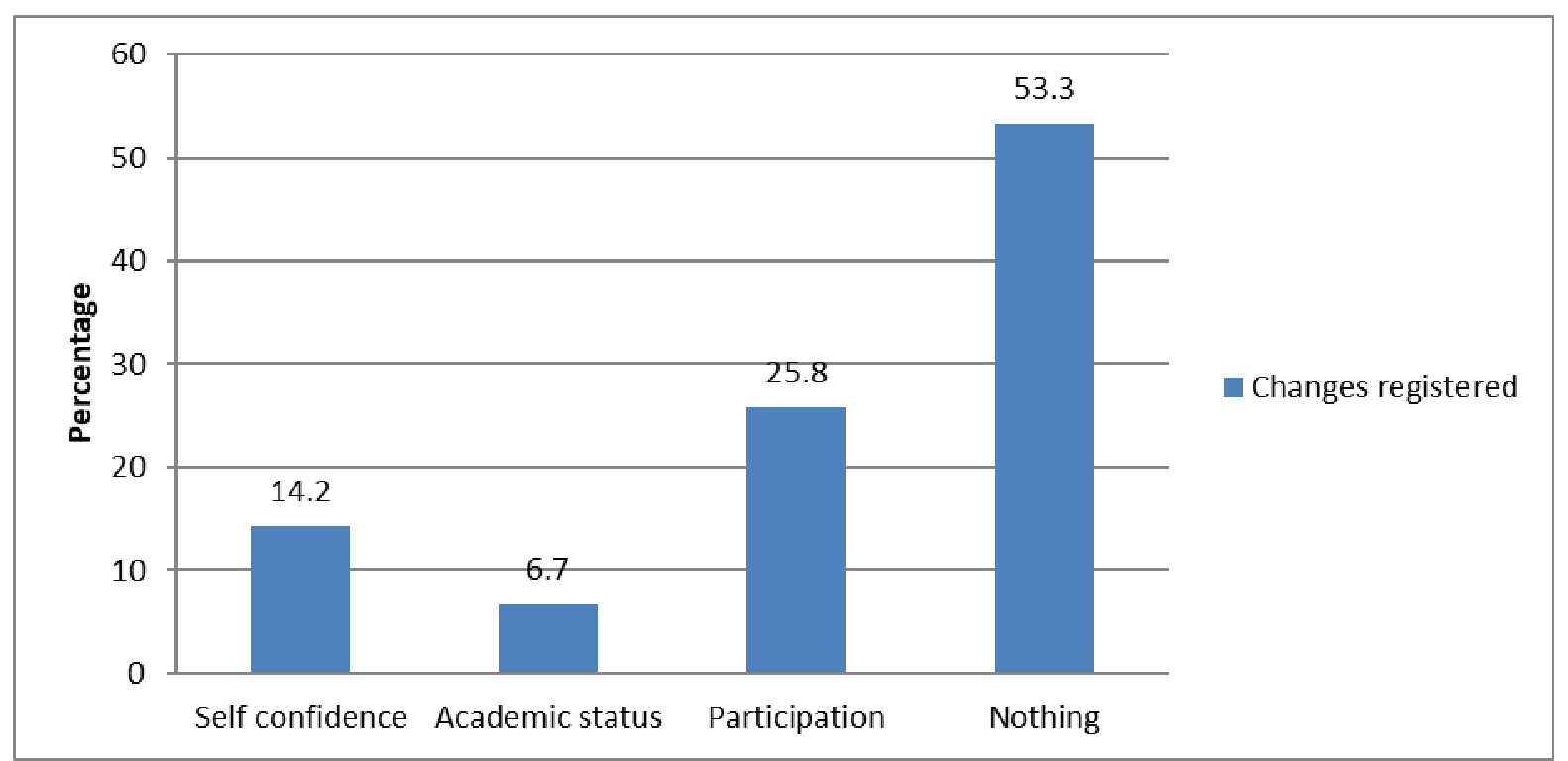

Figure 2: Changes that registered on female students after their participation in the program?

Furthermore, the study tries to get insight the view of participants about their agreement whether substantive equality is achieved in the academia or not. Hence, the finding revealed that $67.5 \%$ of the total participants said that there is no substantive equality in the academic status of both male and female students. While $32.5 \%$ of the participants stated that substantive equality is achieved in the academia. This is very contradictory with the document analysis result in which female students are disproportionately registered lower academic score as compare with their counterparts. For instance out of the total students who registered below 1.5 CGPA, 66\% were females.

Table7: Do you think that substantive equality is achieved in the academia?

\begin{tabular}{|l|c|c|}
\hline Do you think that substantive equality is achieved in the academia & Frequency & Percent \\
\hline No & 81 & 67.5 \\
\hline Yes & 39 & 32.5 \\
\hline Total & 120 & 100.0 \\
\hline
\end{tabular}

Those who reported as substantive equality is achieved in the academia stated indicators for the achievement in the following manner. Majority of them $(48.7 \%)$ confirmed that there is active participation of both male and female students in the teaching and learning process. The second highest ratio of participants reported that there is equal proportion of high achievers of male and female students which constitute $28.2 \%$. On the other hand $15.4 \%$ participants confirmed that the number of students who dismiss due to academic problem is very similar (table 8 below). In this case the finding is not consistent with what is really in the ground and with document analysis result as stated above.

Table 8: Indicators of substantive equality

\begin{tabular}{|l|c|c|}
\hline Indicators of substantive equality & Frequency & Percent \\
\hline Equal proportion of high achievers & $\mathbf{1 1}$ & $\mathbf{2 8 . 2}$ \\
\hline Equal proportion of dismissal cases & 6 & 15.4 \\
\hline Equal proportion of active participants & $\mathbf{1 9}$ & $\mathbf{4 8 . 7}$ \\
\hline All & 3 & 7.7 \\
\hline Total & 39 & 100.0 \\
\hline
\end{tabular}

Those who reported as there was no substantive equality in the academia stated the most important challenges that hinder female students to be competent enough and registered better academic score with their counterparts. In this regard economic problem was reported as the leading challenge (37\%) which negatively affects female students' academic computation. Furthermore, cultural barrier and lack of self-confidence was also mentioned as main challenges equally (23.5\%). Significant percentage (16\%) of participants also stated female students' low attitude towards education hinders their academic achievement to be low.

\section{Conclusion and recommendation}

Conclusion

Affirmative action with the aim to enhance gender equality in education in Ethiopian higher education institutions includes tutorial class, material support and department placement. Even though female students have positive perception towards the program they claimed that the program is not well organized and lacks to better advance their academic performance. 
Raya University has been arranging affirmative action programs like tutorial class, money and material support and priority in departmental placement. From among the programs, tutorial class is the common program that has been given more due attention for female students to improve their academic competency. Majority of female students, however, have no information about the program which is designed to support them in terms of admission and post-admission programs in order to improve their academic achievement and ensure gender equality in academia but they still claim to be beneficiary of all forms of affirmative action in higher education. This shows that female students are not well informed about the manner affirmative action programs are arranged for them at university level like the priority in department placement and tutorial class.

In addition, they are not aware of the contribution of affirmative action on their academic performance. This is because the program cannot create a difference on the academic achievement of the participants of the program. It is ineffective to improve female students' academic performance.

This shows, even though the program is designed at national level, there are weaknesses in implementation which enables to score the required change on the side of female students in higher education institutions.

\section{Recommendation}

Based on the finding of the study on the contribution of affirmative action and attitude of female students towards affirmative action programs in Raya University, the following recommendations are drawn.

* To improve the academic performance of female students and enhance their competency, awareness creation needs to be the priority concern about affirmative action programs and their primary objective.

* To enhance the academic achievement of female students and promote their graduation rate, attention should be given to tackle the most serious challenges that setback female students in the academic arena like financial support by concerned bodies.

* To promote the effectiveness of the program, affirmative action program coordinator should be assigned to practically supervise the implementation of the program and evaluate its impact on the academic achievement of female students. Thus, the government should create administrative structure to formally administer affirmative action program in higher education institutions.

\section{Reference}

- Americans for a Fair Chance: Opportunity through Affirmative Action (2006)

- Asheber, S. A. (2010) Mitigating drought: policy impact evaluation a case of Tigrai Region, Ethiopia

- Constitution of the Federal Democratic Republic of Ethiopia (1995)

- Creswell, J. W. (2007) Qualitative inquiry and research design: Choosing among five approaches, $2^{\text {nd }}$ edition

- Creswell, J. W. (2012) Educational Research: planning, conducting, and evaluating qualitative and quantitative research, $4^{\text {th }}$ edition, Edwards Brothers, Inc. Boston, USA.

- Education and training policy of Ethiopia (1994)

- Ethiopian national policy of women (1993)

- Goshu,T.W (2013) The Law of Affirmative Action in Ethiopia: A Framework for Dialogue.

- Ethiopian journal of human rights Vo. I p 150

- Israel, D. G. (2013) Determining Sample Size University of Florida; IFAS Extention

- Kothri, C. R. (2004) Research methodology: Methods and techniques, new age international (p) Ltd., publishers

- Ministry of Education (MoE) (2005) Education sector development program III (ESDP III); 2005/2006 2010/2011 Program Action Plan(PAP) Federal Democratic Republic of Ethiopia, Addis Ababa, Ethiopia

- $\quad$ Melese,W\&Fenta,G (2009) Trend and causes of female students dropout from teacher education institutions of ethiopia: the case of jimma university

- Ministry of Education (2007) Ethiopian constitutions from /1931-1995/

- Ministry of Finance and Economic Development (MoFED) (2010) Growth and Transformation Plan (GTP); First draft report on Five-year Plan, 2011-2014/15. Federal Democratic Republic of Ethiopia (FDRE), Addis Ababa, Ethiopia

- Negash, T. (2006) Education in Ethiopia: From Crisis to the Brink of Collapse

- Ogbulogo, C. (2010) Research methods; National Open University of Nigeria school of arts and social sciences

- $\quad$ Puszczak, K., Fronczyk, A. and Urbański, M. (2013) Analysis of sample size in consumer surveys

- Reece,D.J.(2011)Revisiting class-based affirmative action in government contracting

- Rowland, J.(1997).Questioning Empowerment: Working with Women in Honduras.

- Semela,T. (2007) Higher Education Expansion and the Gender Question in Ethiopia: A Case Study of Women in a Public University 
- Tsikata,D.(2009) Affirmative action and the prospects for gender equality in Ghanaian politics.

- Women watch (1997-2003) Ethiopian national action plan

- Yasin,A.M.(2013) Affirmative Action for Women in Higher Education and the Civil Service: The Case of Ethiopia 